\begin{tabular}{|c|l|}
\hline Title & A novel preparation of microcast for wood micromorphology using polydimethyl siloxane without digesting cell wall \\
\hline Author(s) & Uraki, Y asumitsu; Nemoto, Junji; Sano, Y uzou \\
\hline Citation & $\begin{array}{l}\text { Journal of Wood Science, 52(2), 163-166 } \\
\text { https://doi.org/10.1007/S10086-005-0740-9 }\end{array}$ \\
\hline Issue Date & 2006-04 \\
\hline Doc URL & http://hdl.handle.net/2115/10520 \\
\hline Rights & The original publication is available at www.springerlink.com \\
\hline Type & article (author version) \\
\hline File Information & JWS_52(2)_163-166.pdf \\
\hline
\end{tabular}

Instructions for use 
Note

\title{
A novel preparation of microcast for wood micromorphology using polydimethylsiloxane without digesting cell wall
}

\author{
Yasumitsu Uraki, Junji Nemoto, Yuzou Sano
}

Graduate School of Agriculture, Hokkaido University, Sapporo 060-8589, Japan

Key word: Microcast, silicon elastomer, PDMS, Cell wall sculpture

Yasumitsu Uraki*, Junji Nemoto, Yuzou Sano (*Corresponding author)

Graduate School of Agriculture, Hokkaido University, N-9, W-9, Kita-ku, Sapporo 060-8589, Japan

Tel. +81-11-706-2817; Fax +81-716-0879

e-mail: uraki@for.agr.hokudai.ac.jp 


\begin{abstract}
We developed a novel method for preparation of microcasts of wood with silicone elastomer (polydimethylsiloxane: PDMS). PDMS was so flexible and elastic that it was possible to isolate the microcasts only by pulling them out from the mold without digesting cell wall after the resin was cured for 2 days at room temperature. The casts of some cell wall sculptures, such as spiral thickenings and bordered pits, had high fidelity. By contrast, the casts of distinctly bordered pits and tails of vessel elements were often deformed or broken. Bars of scalariform perforation plates were always torn and remained in the resin casts. The microcast preparation using PDMS is useful for easy investigation of cell wall sculptures. It might be also useful for micro-fractography of bars of scalariform perforation plates.
\end{abstract}




\section{Introduction}

Microcasting method has been used for examination of wood micromorphology. This technique can visualize the morphology of cavities in wood tissue. Accordingly, studies using this technique provided valuable information about vessel network ${ }^{1}$ and morphology of minute spaces, such as pit cavities. ${ }^{2}$

Resin materials for casts, to date, are polystyrene, ${ }^{2-4}$ polyester, $^{5}$ low density polyethylene $^{1}$, polymethyl methacrylate ${ }^{6}$ and silicon elastomer. ${ }^{7}$ In general, the corresponding monomers penetrated into vacant space of wood as a mold, and were polymerized to yield resins. However, in any case, their methods required to remove the mold by digesting cell wall components. The complete removal of the mold is a key process to yield fine replica with high fidelity. However, this process used hazardous chemicals, because woody cell walls are complex materials that are difficult to digest completely. Thus, it is useful to develop a simple preparation method to take resin-casts.

In this study, we developed a simple preparation method of microcasts using polydimethylsiloxane (PDMS) that was used for making replica or imprint in nanotechnology. ${ }^{8-10}$ Although PDMS is a viscous liquid, it readily penetrates into a cavity of wood cell from openings on transverse surface together with curing agent. After curing, it transforms into flexible elastomer. Therefore, it is possible to isolate the microcasts by only pulling them out from the mold without digesting cell wall. It was expected that the resultant replica reflected the fine structure of the mold with high fidelity.

\section{Materials and methods}

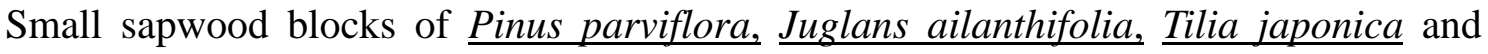
Betula platyphylla var.japonica were used as molds. Transverse face was microtomed to expose flat and clean surface. The mold was placed on liquid PDMS containing curing agent (184 Silicone Elastomer Kit, Dow Corning Co., USA.) in about 2-mm depth for 2 days at room temperature. After curing, the resulting wood block with elasomer was immersed in chloroform for approximately $3 \mathrm{~h}$. The resultant elastomer was pull out from the block using forceps. Similarly, a replica of microtomed radial face of $\underline{B}$. platyphylla var.japonica was prepared by placing the mold on liquid PDMS 
containing the curing agent for 2 days without pressure, and then the replica was peeled off. After trimming by hand-cutting with steel blades, the microcasts were fixed on specimen stubs with electron-conductive paste, coated with Au-Pd by vacuum evaporation and observed under a scanning electron microscope (SEM: JSM5300 or JSM6301F, JEOL Co., Japan).

\section{Results and Discussion}

Preparation of microcasts

PDMS is a viscous liquid, and is transformed into elastomer after curing with a curing agent in a Silicon Elastomer Kit. When one transverse face of each wood block was placed on PDMS containing the curing agent, the PDMS penetrated into void space of the block probably due to the capillary phenomenon. The penetrated PDMS ascended up to $2 \mathrm{~cm}$ in height. In this procedure, it took 2 days for PDMS penetration and curing. When PDMS was cured within $45 \mathrm{~min}$ at $100{ }^{\circ} \mathrm{C}$ according to the curing protocol of PDMS kit, bubbles were formed in the resultant elastomer. As this bubble formation was probably due to the evaporation of water in mold, it was expected to be overcome by degas prior to curing. However, the treatment was not successful, because PDMS absorbed moisture in air during the penetration. In contrast, bubble was not at all or hardly formed when the resin was cured at room temperature. Therefore, we processed the penetration and curing at room temperature, although it took longer time than did at $100^{\circ} \mathrm{C}$.

We sometimes failed to pull out the cured elastomer, because it tightly fixed to the mold. The treatment with chloroform prior to the isolation of microcasts was effective to facilitate pulling out the elastomer from the mold, probably due to suppress adhesion between the mold and the elastomer. It was possible to take vessel casts in several mm length by using chloroform soaking (Fig. 1). Thus, the chloroform treatment is useful to prepare microcasts without digesting cell wall components. In the process of casting of radial face, the microcast was easily peeled off the mold without chloroform treatment, because the microcast did not penetrate but existed on the surface of the mold. 
A microcast of vessels were selectively prepared (Fig. 1). Such a selective isolation of vessel casts had been attempted by the control of the viscosity of resin ${ }^{1}$ or by removing other elements using sonication. ${ }^{3}$ In the case of our method, not only the viscosity but preparation procedure also contribute to the selective isolation. It was most likely that casts of the other elements, such as wood fibers, were torn from the vessel cast and left in the mold when the casts were longitudinally pulled out from the transverse faces. Thus, the method using PDMS was useful to examine the structure of vessels. However, it was difficult to obtain long casts of vessels because the casts were often broken during the pulling-off process. In addition, artificial deformation of vessel-casts often took place even if long and intact casts were obtained (Fig. 1). It is most likely that the microcasts are too flexible to preserve the three-dimensional arrangement of such long structures. Thus, this method is not adequate to examine the arrangement and network of vessels, although it is useful to examine the micro-morphology of each vessel.

PDMS showed high fidelity at fine structural level. The casts clearly demonstrated the morphology of minute spaces, such as lumina of tracheid tip (Fig. 2), and cell wall sculptures, such as spiral thickenings (Fig. 3) and pits (Fig. 4). PDMS replication indicated fidelity in submicron level as previously reported. ${ }^{9}$ Therefore, no microfibril replica was observed in this method.

There were also limitations in our microcast preparation using PDMS. Fig. 5 shows bars of scalariform perforation plate of $\underline{B}$. platyphylla var. japonica, which are torn and kept in the resin casts. It is impossible to prevent such artificial destruction of this type of minute structures, which are present in larger cavities, during preparation. However, it is conversely possible to use our technique for micro-fractography of such minute structures.

In addition, it was also difficult to prevent deformation and destruction of the resin casts of some other structures. Casts of vessel element tails and wood fiber tips were often found to be deformed (Fig. 4 and 6). Casts of cavity of distinctly bordered pit were often torn away, as well (Fig. 4). It is because strong stress is loaded to the casts during pulling out.

Our method of resin-casting replica has some limitations and demerits in studies of wood micromorphology. However, this method has relevant characteristics which are quite different from those in previous methods. The cured PDMS as a replica resin is so 
flexible and elastic that we can isolate the casts by pulling out without the use of hazardous chemicals to digest of wood tissues. It is expected that this replica preparation is not only simple but also unique and useful for some analyses, such as a micro-fractography.

Acknowledgement

Part of this work was financially supported by a Grant-in-Aid for Scientific Research from Japan Society for the Promotion of Science (\#15208016). 


\section{References}

1. Fujii T, Hatano Y (2000) The LDPE resin-casting method applied to vessel characterisation. IAWA Journal 21: 347-359

2. Taneda K, Kawakami S, Ishida S, Ohtani J (1979) Observation of the polymer in wood-polymer composite. 1. Dissolution of wood substance in WPC and shape of the polymer cast. Mokuzai Gakkaishi 25: 209-215

3. Fujii T (1993) Application of a resin casting method to wood anatomy of some Japanese Fagaceae species. IAWA Journal 14: 273-288

4. Kitin P, Sano Y, Funada R (2001) Analysis of cambium and differentiating vessel elements in Kalopanax pictus using resin cast replicas. IAWA Journal 22: 15-28

5. Stieber J (1981) A new method of examining vessels. Ann Bot 48: 411-414

6. Fujii T (1993) Application of resin casting method to wood anatomy. Plant Morphology 5: 3-17

7. André JP (2000) Heterogeneous, branched, zigzag and circular vessels: unexpected but frequent forms of tracheary element files: description-localization-formation. In: Savidge J, Barnett $\mathrm{J}$ and Napier R (eds) Cell and molecular biology of wood formation. BIOS, Oxford, pp 387-395

8. Xia Y, McClelland JJ, Gupta R, Qin D, Zhao XM, Sohn L, Celotta RJ, Whitesides GM (1997) Replica molding using polymeric materials. A practical step toward nanomanufacturing. Adv Mater 9: 147-149

9. Ohzono T, Fukuda N, Nishikawa T, Shimomura M (2002) Imprint of honeycomb pattern on PDMS Elastomer. Int J Nanosci 1: 569-573

10. Kim DH, Lin ZQ, Kim HC, Jeong U, Russell TP (2003) On the replication of block copolymer templates by poly(dimethylsiloxane) elastomers. Adv Mater 15: 811-814 
Figure caption

Fig. 1. Selective isolation of vessel casts of Juglans ailanthifolia.

Fig. 2. A part of microcast of Pinus parviflora, showing the morphology of lumen of tracheid tip.

Fig. 3. A part of vessel element cast of Tilia japonica, showing imprints of spiral thickenings.

Fig. 4. Resin cast from a radial section of Betula platyphylla var. japonica, showing casts of minutely bordered pits on wood fiber walls and deformed casts of wood fiber tips.

Fig. 5. Resin cast of a vessel of Betula platyphylla var. japonica. Arrows indicate bars of scalariform perforation plate which were torn and remained in the cast.

Fig. 6. Microcast of vessel of Betula platyphylla var. japonica. An arrow indicates a tail of vessel element which was turned up by pulling out. 


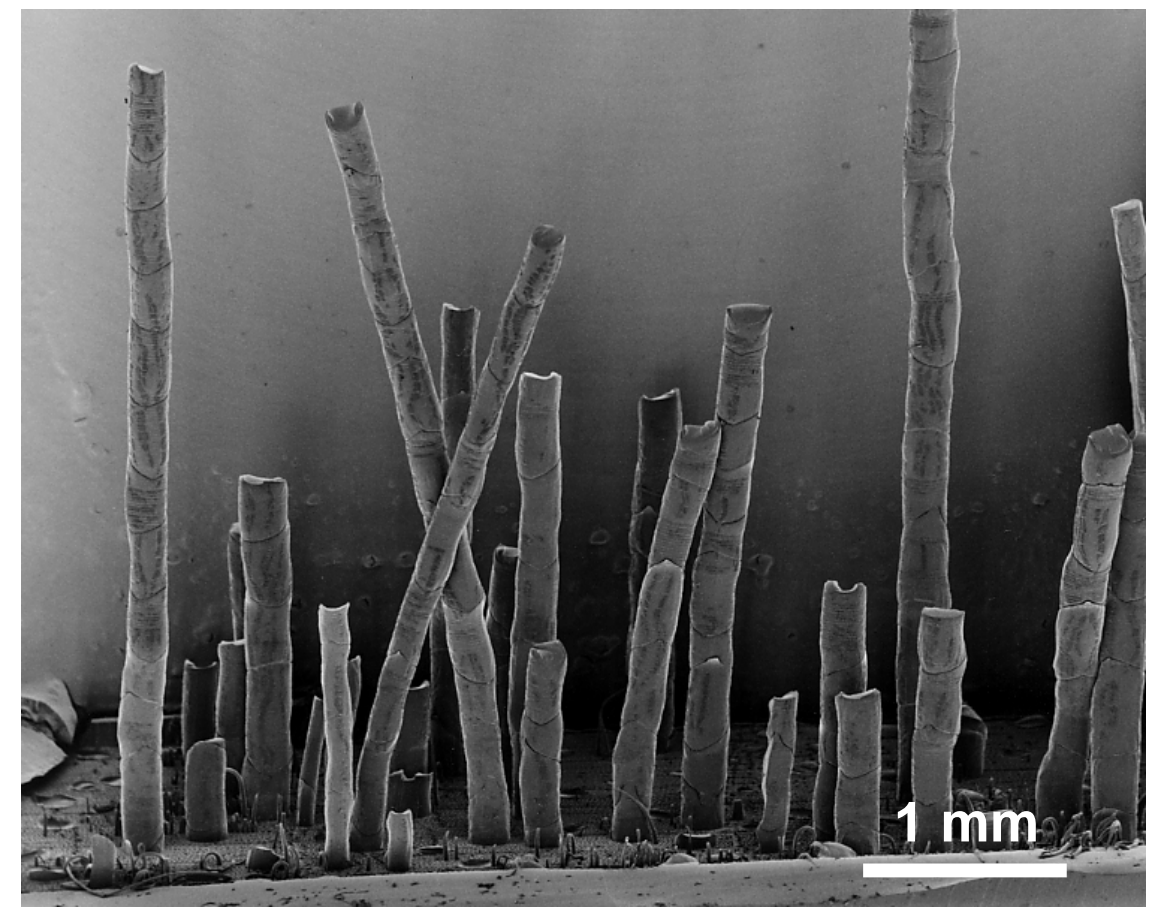

Fig. 1. Selective isolation of vessel casts of Juglans ailanthifolia. 


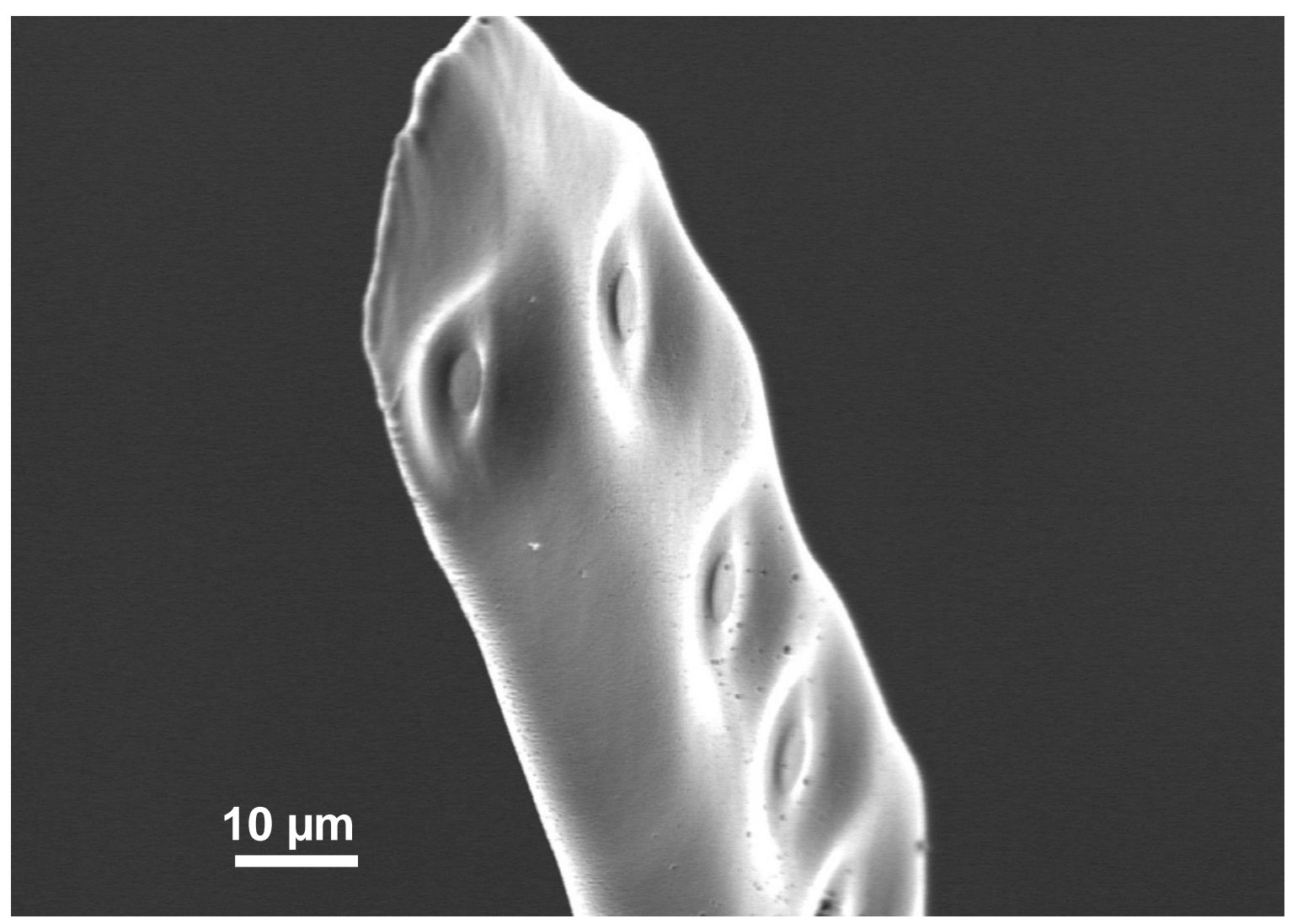

Fig. 2. A part of microcast of Pinus parviflora, showing the morphology of lumen of tracheid tip. 


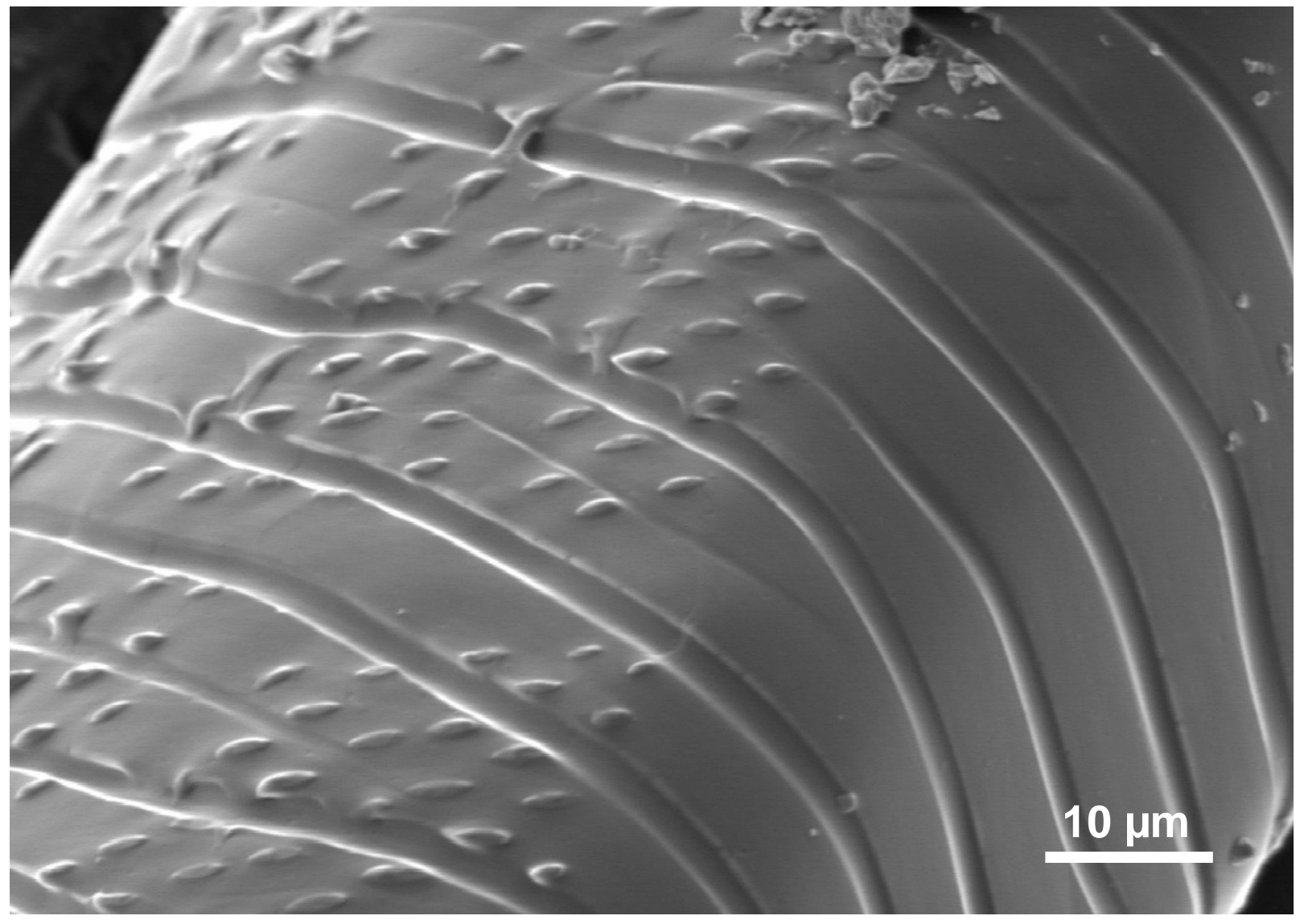

Fig. 3. A part of vessel element cast of Tilia japonica, showing imprints of spiral thickenings. 


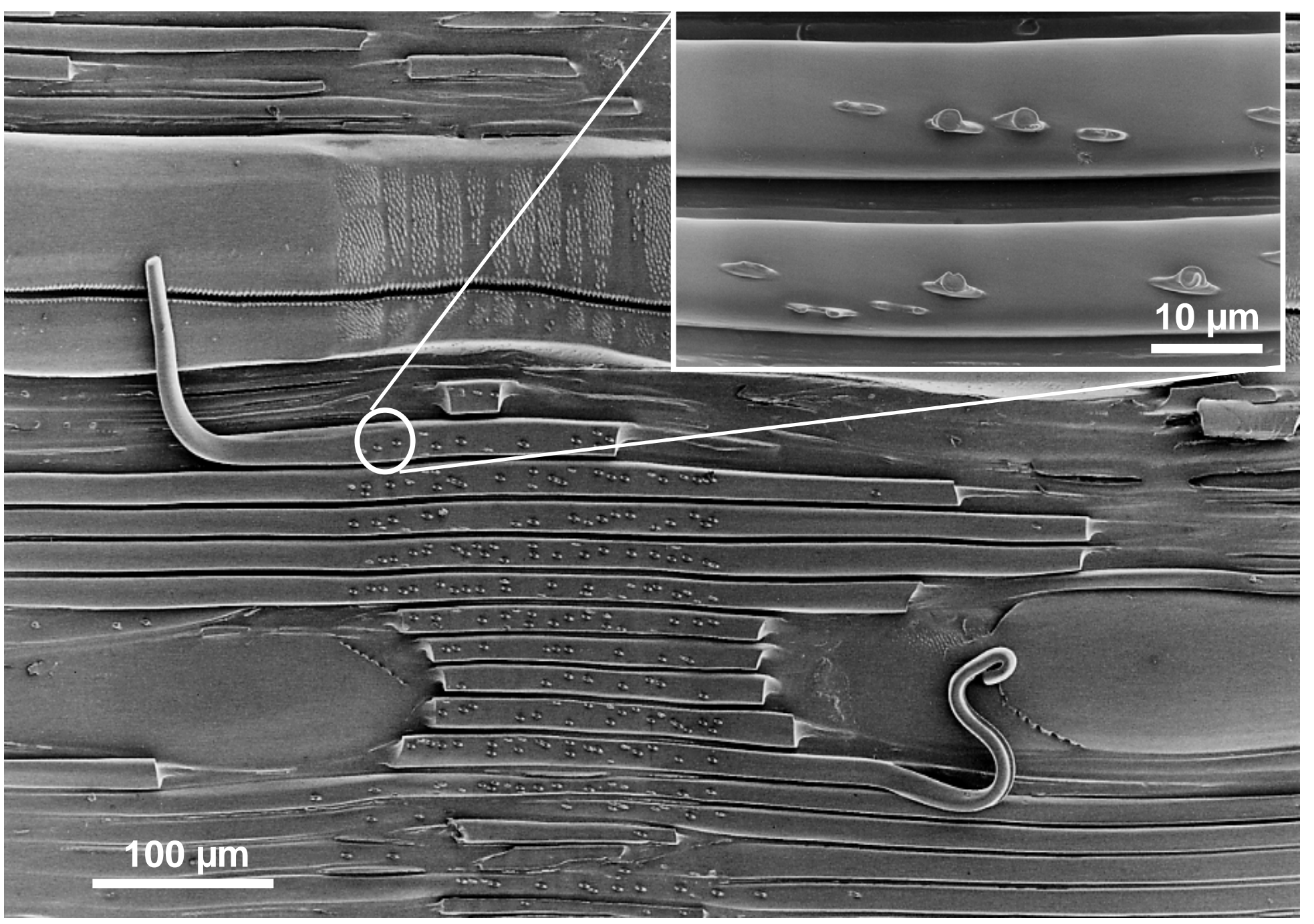

Fig. 4. Resin cast from a radial section of Betula platyphylla var. japonica, showing casts of minutely bordered wood fiber pits and deformed casts of wood fiber tips. 


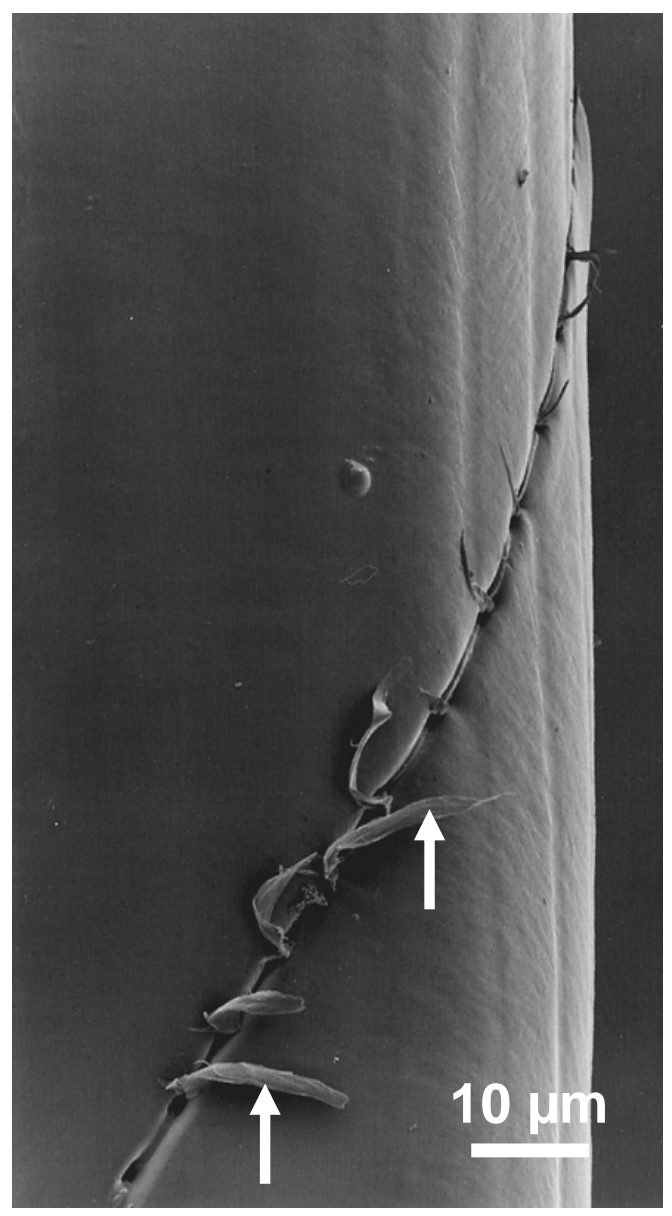

Fig. 5. Resin cast of a vessel of Betula platyphylla var. japonica. Arrows indicate bars of scalariform perforation plate which were torn and remained in the cast. 


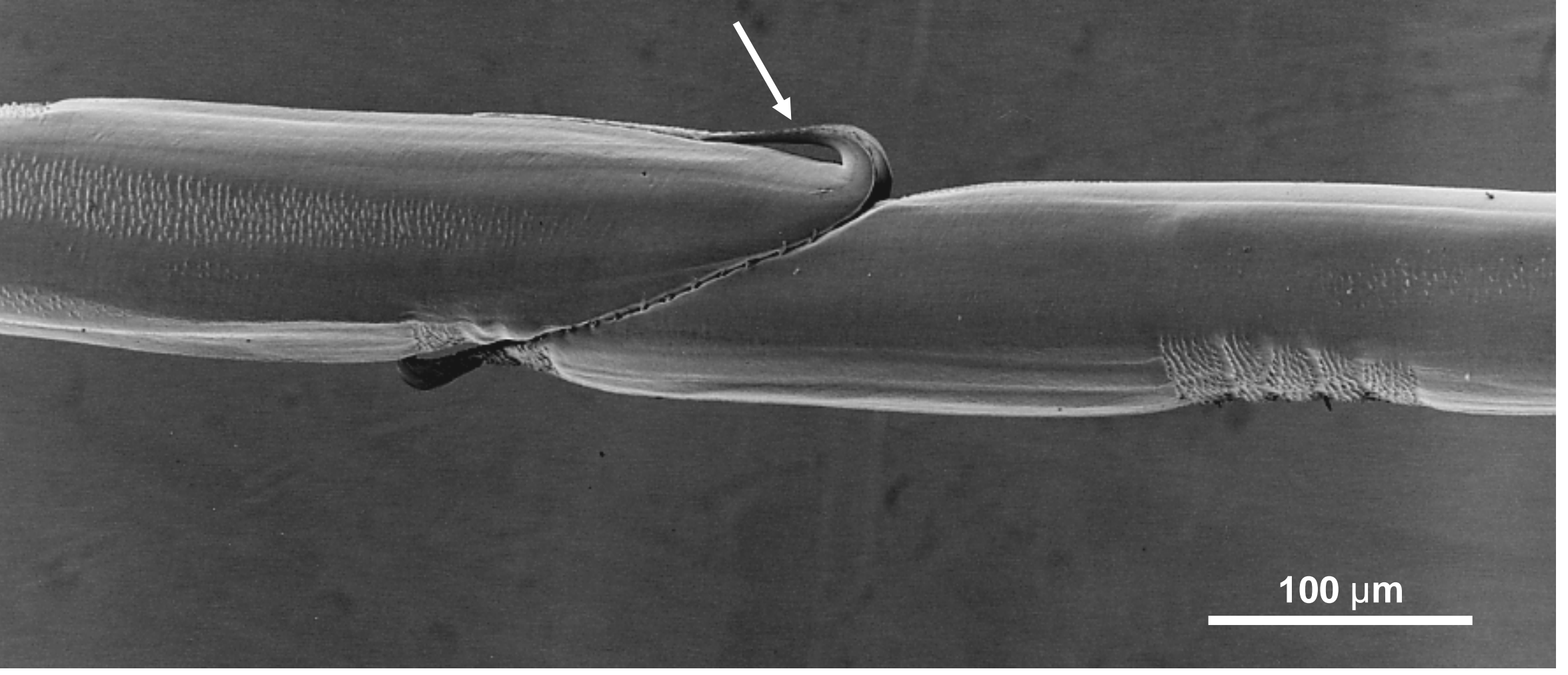

Fig. 6. Microcast of vessel of Betula platyphylla var. japonica. An arrow indicates a tail of vessel element which was turned up by pulling out. 